\title{
CONSCIENTIZAÇÃO E EDUCAÇÃO NA ESCOLA PÚBLICA: $O$ DESCARTE INDEVIDO DO ÓLEO E SEUS EFEITOS NO MEIO AMBIENTE
}

\author{
Aline Ferreira de Souza Pereira ${ }^{1}$ \\ Carlos Caetano Oliveira dos Santos ${ }^{1}$ \\ Cristina Zukowsky-Tavares ${ }^{1}$ \\ Vanessa Maria Sales Raymundo ${ }^{1}$
}

Resumo: As agressões ao meio ambiente têm se tornado cada vez mais significativas nas últimas décadas. Os óleos alimentares são resíduos gerados diariamente por lares e indústrias alimentícias e descartados erroneamente em diferentes locais. Esta investigação objetivou refletir nessa problemática e seus efeitos no meio ambiente. Foi uma pesquisa de natureza qualitativa que levantou opiniões e percepções sobre a questão do descarte indevido do óleo. Utilizou-se de um grupo focal de avaliação para o diagnóstico inicial e final, após o programa de intervenções em sala de aula . A amostra foi constituída de dez estudantes do nono ano de uma escola estadual da Zona sul da cidade de São Paulo. Concluiu-se que os sujeitos como um todo (80\%) expressaram mudanças qualitativas com relação à consciência e compreensão da realidade, agregando novos conhecimentos em relação ao impacto do óleo no meio ambiente de forma mais crítica e reflexiva.

Palavras-chave: Poluição; Descarte do Óleo; Educação Ambiental; Meio Ambiente; Escola Pública.

${ }^{1}$ Centro Universitário Adventista de São Paulo (UNASP). E-mails: aline.enila@ymail.com cristina.tavares@unasp.edu.br.

Revbea, São Paulo, V. 9, N 1:102-115, 2014. 


\section{Introdução}

Agressões ao meio ambiente são temas frequentemente discutidos na mídia de forma geral. O ser humano começa a sentir bem de perto a revolta do planeta em relação aos maus tratos sofridos nas últimas décadas em nosso meio. O desequilíbrio ambiental tem se agravado cada vez mais devido à negligência humana em relação ao mau uso do espaço e dos recursos que a natureza nos oferece.

Um preço muito alto a ser pago pelo próprio homem é a insaciável sede consumista desencadeada a partir da Revolução Industrial, potencializada com os avanços tecnológicos dos meios de produção e universalizada pela mídia na era da globalização. A febre do consumo tem custado muito caro para o homem e o meio ambiente (TRIGUEIRO, 2005).

Catástrofes ambientais fazem parte rotineiramente dos noticiários apresentando problemas relacionados a vazamentos petrolíferos, queimadas, lixo radiativo, gases poluentes dentre outros temas que nos assustam ao compreendermos seus resultados. Esses desastres trazem prejuízo de toda ordem, acarretando morte de pessoas, prejuízos econômicos e ambientais. Muitos pesquisadores consideram tais prejuízos como resposta da natureza ao homem que se vê cada vez mais pressionado a tomar medidas satisfatórias que freiem os desastres ambientais e proponham soluções práticas e eficientes para que o homem possa progredir em todos os aspectos e viver em equilíbrio com o meio ambiente. Talvez a melhor proposta seja a busca pelo justo equilíbrio entre o desenvolvimento econômico, proteção e restauração do ambiente, como única forma de garantir qualidade de vida para as espécies presentes e futuras gerações (PRADO, 2006).

Necessitamos reencontrar o equilíbrio para a garantia da excelência de forma que todas as espécies vivam em níveis sub-ótimos, interagindo e propiciando a vida já que a vida só acontece quando há interação com os outros elementos da natureza (GONÇALVES, 1984).

Por meio de fatores ambientais os seres vivos fazem adaptações para que seu desenvolvimento ocorra e alguns fatores abióticos como temperatura, luz, água, gases atmosféricos, espaço físico e fogo funcionam como fatores limitantes que influenciam diretamente o ciclo de vida das espécies.

Responsável pela garantia de vida dos seres vivos em geral e uma das bases da organização social, a água está envolvida direta ou indiretamente em todas as atividades humanas, na agricultura, pecuária, atividades domésticas, geração de energia e lazer. No setor siderúrgico, por exemplo, são gastos 15 mil litros de água para cada tonelada de aço produzida. O consumo de água de um país impacta fortemente em sua economia (TRIGUEIRO, 2005).

$\mathrm{Na}$ expressão de Odum (1998) a água, sendo necessária para todo o protoplasma, é considerada um fator limitante em ambientes terrestres e aquáticos, controlando as taxas de umidade do ar, salinidade dos oceanos, evaporação e perda de água nos organismos pelo processo de osmose. 
Por meio da atividade dos processos industriais, das condições de vida e do patrimônio cultural podem-se alterar de maneira indesejável as características físicas, químicas e biológicas do ar, água e solo e tais alterações podem afetar de modo prejudicial a vida do homem e das outras espécies ou deteriorar nossos recursos em materiais que são considerados poluição (ODUM, 1988).

No entendimento de Odum (2004) muitos são os agentes que podem poluir os recursos hídricos, e, a forma mais comum de poluição hídrica é a proveniente de substâncias orgânicas, ocorrendo pelo lançamento de esgotos domésticos nos corpos d'água com poluentes que podem interferir nos níveis sub ótimos dos fatores limitantes que são a base do equilíbrio ecológico. Uma das principais preocupações neste contexto e quanto à geração de resíduos líquidos refere-se aos óleos e graxas: óleos, ceras, ácidos graxos oriundos de alimentos consumidos diariamente tais como gordura vegetal, gordura animal, manteigas, margarinas, óleos vegetais, além dos lubrificantes utilizados em indústrias, refeitórios, lares e restaurantes. Os óleos alimentares surgem como um grande problema ambiental. Gerados diariamente nos lares e estabelecimentos, e, por falta de processo de educação eficaz acabam sendo erroneamente descartados nas pias, vasos sanitários, seguindo para os sistemas de esgotos e causando danos como entupimento nas encanações e encarecimento dos processos das Estações de Tratamento e Poluição Ambiental. Sabe-se que cada litro de óleo pode contaminar até um milhão de litros de água o que é equivalente ao consumo de uma pessoa em 14 anos. Em contato com a água do mar, resíduos de óleo passam por reações químicas, e, por meio das ações de bactérias anaeróbicas, o produto resultante dessas reações é a emissão do gás metano. Sabe-se que o metano é um dos principais gases que causam o efeito estufa que contribui para o aquecimento da Terra. Pelo fato do óleo ser mais leve que a água, ficando na superfície, ele cria uma barreira que dificulta a entrada de luz e a oxigenação da água, comprometendo assim a base da cadeia alimentar aquática (CANAL RURAL, 2010).

Restrepo (2012) enfatiza que a prevalência de um ambiente saudável como direito fundamental dos seres humanos requer ações para diminuir os fatores exógenos específicos que contribuem para a poluição. O tratamento adequado que deve ser dado ao óleo utilizado para cozinhar como um resíduo líquido que polui os recursos hídricos muitas vezes de forma irreversível, mais do que um desafio ambiental é uma problemática social:

Um dos grandes problemas do mundo e para a sociedade, é saber o que vai fazer com a grande quantidade de lixo que se é produzido no meio social como, por exemplo, o óleo de origem vegetal ou animal que sempre foi utilizado pelo ser humano com vários objetivos, entre um deles o de ser usado na fritura de alimentos, contudo após algum tempo utilizado, ele passa a não ser bom para o uso de frituras, por passar a ter aromas e cheiros dos alimentos que foram fritos anteriormente, sendo 
assim tendo que ser descartado. Assim, muitos o jogam direto na pia ou no quintal e ao cair no solo ou nas redes de esgoto, eles acarretam a poluição do solo, da água superficial, dos lençóis subterrâneos e das redes de drenagem, passando a deixar de ser uma solução individual e a passar a ser um problema social (SEGATTO, 2013, p.2122)

No Projeto de Lei 166-2007 (AMAZONAS, 2007), encontra-se destacado uma alerta de Braga (2002) de que como dano do óleo de cozinha ao meio ambiente ocorrerá também a vedação dos estômatos das plantas e órgãos respiratórios dos animais, a impermeabilização das raízes de plantas e uma ação tóxica para os seres aquáticos. No caso de despejo direto no solo a impermeabilidade da terra é um dos principais responsáveis pela dificuldade de escoamento da água da chuva, propiciando mais enchentes. Sabe-se também que quando descartado no solo sob o sol, a temperatura do óleo pode chegar a $60^{\circ} \mathrm{C}$, matando animais e vegetais microscópicos e repercutindo no meio ambiente de forma indesejável.

A sociedade como um todo poderia construir a consciência de que é responsável pela preservação do meio em que vive e, para tanto, é necessário educar a população em geral.

De acordo com a Lei de $\mathrm{n}^{\circ}$. 3325, de 17 de dezembro de1999 artigo $2^{\circ}$ "A Educação Ambiental é um componente essencial e permanente da educação estadual e nacional, devendo estar presente, de forma articulada, em todos os níveis e modalidades do processo educativo, em caráter formal e não formal'.

O "Tratado de Educação Ambiental para Sociedades Sustentáveis e Responsabilidade Global" assinado durante a conferência Rio'92, afirma que a Educação Ambiental é um processo de aprendizagem constante, que tem como base o respeito a todas as formas de vida. E pela Educação que se promovem valores morais e ações que contribuem para que haja mudanças humanas e sociais, contribuindo para o crescimento de sociedades mais justas e ecologicamente equilibradas, que mantenham entre si relação de interdependência e diversidade. Dessa forma, a responsabilidade surge a nível individual, prosseguindo para a coletividade em nível local, nacional e planetário.

Muitas manifestações têm ocorrido em favor do meio ambiente. A Agenda 21 é um documento que estabelece a importância de cada país em se comprometer com as questões ambientais e propõe que tanto o governo quanto as instituições privadas cooperem com o mesmo. No capitulo 36 da Agenda 21, a educação é definida como um processo que busca,

(...) desenvolver uma população que seja consciente e preocupada com o meio ambiente e com problemas que the são associados. Uma população que tenha conhecimentos, 
habilidades, atitudes, motivação e compromisso para trabalhar individual e coletivamente na busca de soluções para problemas existentes e para a preservação dos novos (...).

Alternativas têm sido estudadas para o reaproveitamento adequado dos resíduos de óleo de cozinha como a produção de sabão, massa de vidraceiro, ração animal, bem como " a produção do biodiesel dentro de um sistema integrado de inclusão" que é capaz não só de "apresentar viabilidade econômica como também ser apontado como resposta ao apelo ambiental quando o resíduo de óleo deixa de ser despedido nos esgotos para transformar-se em fonte alternativa de combustível" (FERNANDES et al., 2008, p.8).

Paulo Freire (1983) discute que o processo educacional deveria desencadear no individuo um conhecimento crítico uma vez que tal processo ocorre com base na reflexão possibilitando ao mesmo que se posicione e de forma crítica no cotidiano. Apenas quando um homem compreende e se aproxima de sua realidade, que no caso dessa investigação se refere ao descarte indevido do óleo na natureza é que poderá ser capaz de levantar hipóteses sobre os desafios impostos e propor soluções ao mesmo.

No entendimento de Guimarães (1995) também é essencial e necessário o exercício da prática da Educação Ambiental, para que não ocorram manifestações sem propósito e reflexões que não promovam ações concretas, defendendo sempre a ideia de que é necessário unir a reflexão à prática. Neste aspecto, Jacobi (2005) continua afirmando que as práticas educativas devem buscar propostas pedagógicas mais direcionadas a mudanças de hábitos, atitudes e práticas sociais. Devem-se elevar as questões ambientais a um plano de viabilidade na agenda política universal e fazer com que a proposta de cuidado com o meio ambiente interfira nas decisões políticas e sociais como um todo.

E foi nesse sentido que optamos por uma pesquisa na área que agregasse um breve período de intervenção com estudantes de Ensino Básico formadores de opiniões e esse trabalho foi realizado com a intenção de investigar a Educação Ambiental e suas vertentes como um meio de colaborar com a formação de uma geração de adolescentes e famílias mais conscientes de forma técnica e política dos prejuízos acarretados pelo descarte indevido de óleo na natureza.

Esta investigação objetivou construir novos conceitos teórico-práticos em Educação Ambiental por meio de uma pesquisa interventiva no ensino fundamental sobre o descarte indevido de óleo no ambiente. 


\section{Materiais e métodos}

A pesquisa de natureza qualitativa levantou opiniões e percepções de estudantes sobre a questão do descarte do óleo no meio ambiente fazendo a partir do diagnóstico inicial, um breve projeto de intervenção que foi depois avaliado para montar o quadro das conclusões finais e encaminhamentos. $O$ principal instrumento de coleta de dados dessa pesquisa foi o "grupo focal".

Essa técnica de pesquisa reúne um grupo de 6 (seis) a 15 (quinze) sujeitos de pesquisa que sob a orientação do roteiro elaborado pelos pesquisadores discutem sobre determinado assunto em pauta que seja comum a todos os elementos do grupo (GATTI, 2005). As informações dos grupos focais foram registradas pelos estudantes pesquisadores por meio de transcrição de gravação.

A pesquisa realizou-se na Escola Estadual Prof. ${ }^{\text {a }}$ Beatriz de Quadros Lemes localizada na região sul da cidade de São Paulo no ano de 2010. O ambiente foi selecionado por ser um dos locais de estágio dos licenciandos pesquisadores no curso de Ciências Biológicas. Nessa escola os pesquisadores também obtiveram a autorização e apoio para a realização da pesquisa por parte dos gestores e docentes.

A amostra foram 10 (dez) alunos do $9^{\circ}$ (nono) ano do ensino fundamental. O critério de seleção da amostra foi convidar alunos formadores de opinião concluintes do ensino fundamental, inferindo que poderiam se tornar multiplicadores das ideias sobre a preservação ambiental após o período de intervenção e conscientização. Com o auxílio do corpo docente da escola, identificaram-se na turma estudada os alunos com o perfil de formadores de opinião em classe. Esses estudantes foram informados das questões éticas envolvidas na pesquisa, seus objetivos, que tinham liberdade de escolha na participação e que suas identidades seriam preservadas. Entregou-se para cada aluno um Termo de Consentimento Livre e Esclarecido para ciência e autorização dos responsáveis pelo participante na pesquisa.

\section{Grupo focal inicial}

Os dados iniciais e percepções dos estudantes sobre o assunto foram coletados na forma de um grupo focal inicial. No primeiro encontro os alunos selecionados foram retirados da classe e levados para um ambiente separado onde fizeram um círculo. Inicialmente foram colocadas algumas gravuras de problemas ambientais e, entre elas, a gravura do óleo. Tal procedimento permitiu que cada participante escolhesse a gravura que mais the chamou a atenção e refletisse sobre a mesma.

Essa introdução seguiu-se de uma discussão orientada por um roteiro de questões. Os dez alunos do nono ano comentaram os assuntos propostos e os pesquisadores anotaram e gravaram os dados do diagnóstico inicial com as ideias e conhecimentos prévios dos estudantes sobre o tema em questão. Para sensibilizar os estudantes para o debate nesse primeiro Grupo Focal os

revista brasileira educação ambiental 
pesquisadores apresentaram imagens relacionadas à degradação ambiental e o descarte do óleo, partindo de alguns momentos de discussão coletiva inicial.

Algumas gravuras para sensibilização utilizadas no primeiro grupo focal são apresentadas a seguir (Figura 1):

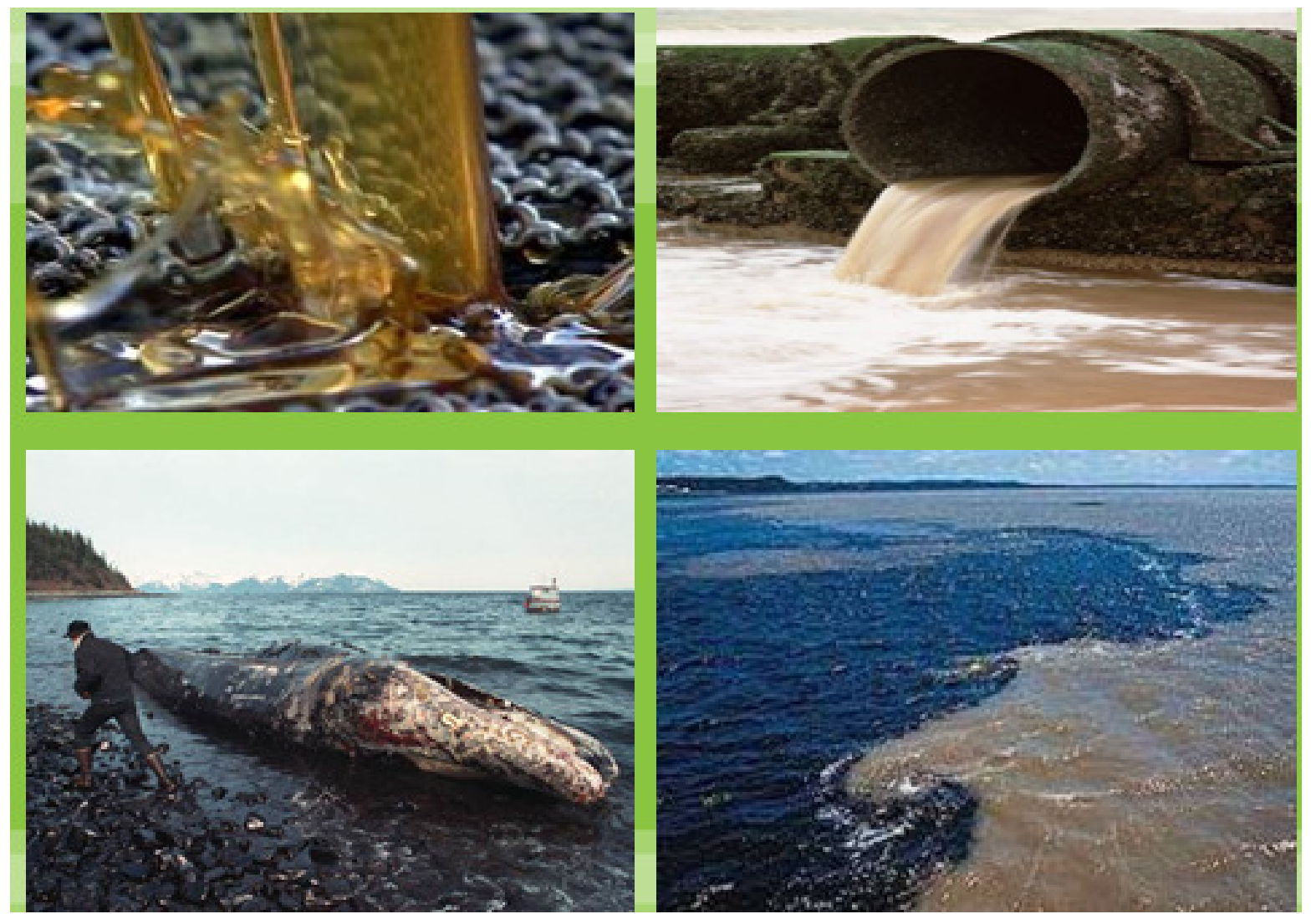

Figura 1: Imagens utilizadas na sensibilização inicial com os estudantes.

Fonte: Arquivo dos pesquisadores.

\section{Intervenções}

A partir das informações iniciais, os estudantes pesquisadores montaram um programa de conscientização sobre o impacto do óleo no meio ambiente. Foram disponibilizadas quatro aulas de Ciências com a classe dos sujeitos de pesquisa para a realização do programa de conscientização. O programa contou com algumas estratégias interventivas como: aulas expositivas dialogadas voltadas para a temática, grupos de discussão, exposição de cartazes, e uma criativa palestra de conscientização e preservação ambiental realizada pelos próprios sujeitos de pesquisa no último encontro.

$\mathrm{Na}$ primeira aula ministrada apresentou-se a proposta do trabalho e 
"caixinha surpresa" que continha diferentes atividades de conscientização a serem realizadas pelos grupos (teatro, paródia, sarau, experiência e gincana). Escolheu-se um representante de cada grupo e sorteou-se a atividade a ser realizada na última aula de conscientização. Levantou-se a proposta da criação de um ponto de coleta do óleo vegetal na escola para confecção de sabão em uma das aulas. A aula seguinte destinou-se à apresentação da temática, de forma dialogada e reflexiva destacando suas causas e consequências. $\mathrm{Na}$ terceira aula propôs-se aos alunos a elaboração de cartazes para exposição nos corredores da escola. Na quarta aula, os grupos, com tempo estipulado pelos pesquisadores apresentaram para a sala de aula em que estudam as atividades propostas no primeiro encontro.

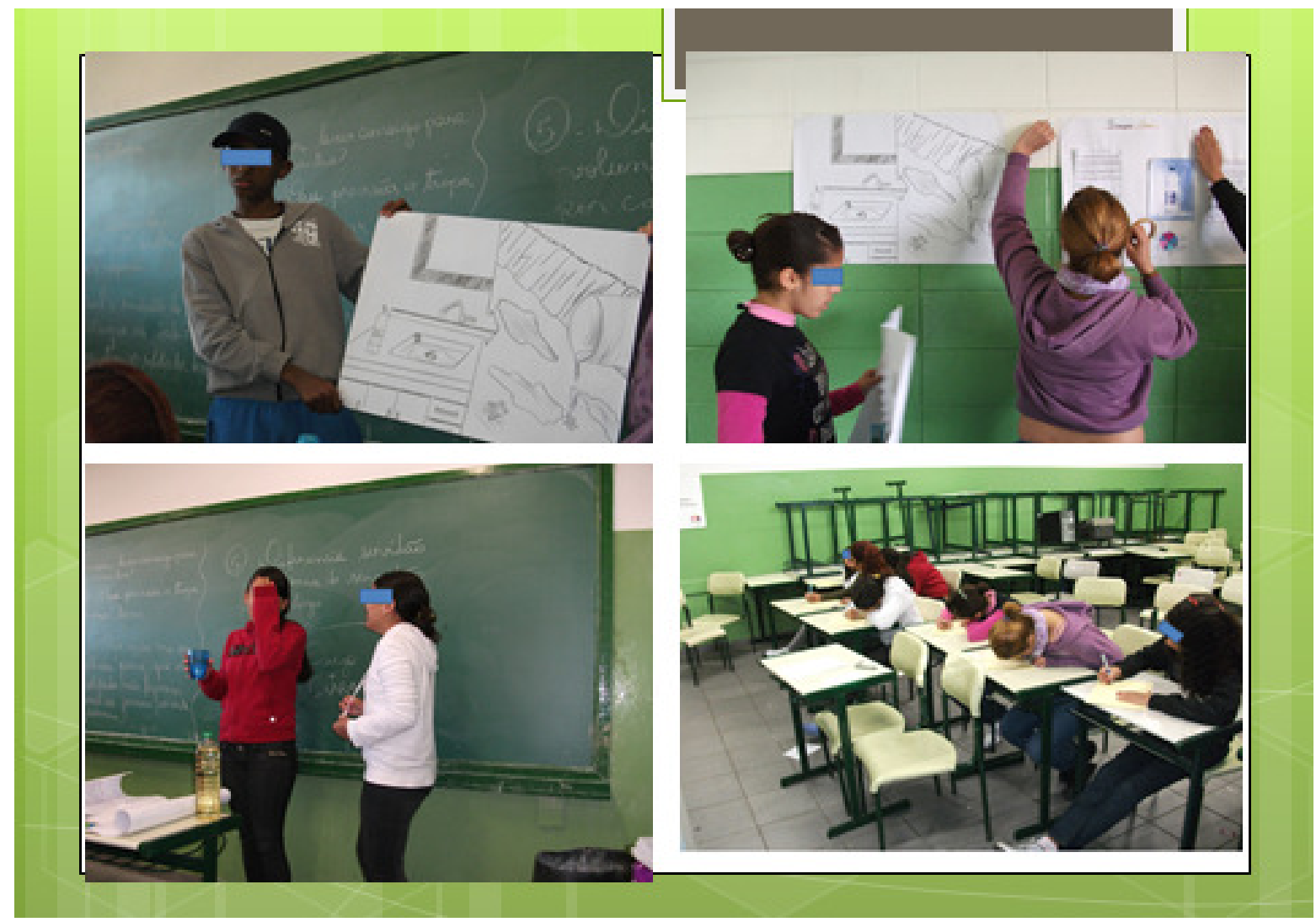

Figura 2: Atividades de Intervenção com os alunos do nono ano na escola pública. Fonte: Arquivo dos pesquisadores.

\section{Grupo focal de avaliação}

A pesquisa findou-se com o grupo focal de avaliação, utilizando-se do mesmo roteiro do grupo focal inicial. Fez-se um levantamento qualitativo de aprendizagens conquistadas e conflitos ocorridos após as intervenções. Os pesquisadores anotaram e gravaram as informações, e levaram para análise. 


\title{
Apresentação de resultados e discussão
}

Ao discutirem no Grupo Focal se dentro de suas próprias casas os estudantes poderiam causar danos ao meio ambiente eles afirmaram prioritariamente que o óleo vegetal utilizado na cozinha agride o meio ambiente e nem sempre é reciclado. Destacaram também que esses cuidados previnem a poluição dos recursos hídricos. Na discussão dos resultados apresentaremos em negrito as falas dos sujeitos de pesquisa que foram designados como E1, E2, E3...:

"(...) Jogando óleo de cozinha na pia ou em qualquer lugar que saia nos rios e polui" E7

Ao discutirem o mesmo questionamento ao final do processo alguns estudantes apresentaram uma resposta mais elaborada (E1, E6, E8, E10) como, por exemplo, a que foi registrada pelo estudante 6 (E6):

\begin{abstract}
"Eu aprendi que jogando óleo vai prejudicar a gente e o meio ambiente (...) vai para o esgoto, vai para os rios e o óleo vai ficar por cima causando problemas aos seres vivos aquáticos e a respiração".
\end{abstract}

Outro estudante demonstrou uma conscientização maior ao final do percurso que se expandia para outras questões da Educação Ambiental:

"A maioria das vezes a gente causa danos ao meio ambiente em casa mesmo, demorando no banho, quando lavamos a louça e deixamos a torneira ligada ou até jogando óleo na pia." (E1)

Como agentes de uso doméstico que silenciosamente podem agredir o meio ambiente comentaram no primeiro grupo focal que esses agentes seriam o sabão, detergente e o óleo. Após a intervenção alguns detalhes citados apontam a melhoria de qualidade na aprendizagem de alguns estudantes (E4, $E 9, E 6, E 5, E 7, E 8)$ principalmente no que se refere à conscientização sobre o tema, como declarou um dos sujeitos:

"Há muitas coisas, como o óleo e o lixo nos córregos. As pessoas fazem isso sabendo que vai prejudicar elas mesmas."

Ao discutir no grupo focal de avaliação as consequências do descarte do óleo no ambiente os sujeitos como um todo (80\%) expressaram mudanças qualitativas com relação à consciência e conhecimento envolvido nessa área. 
Os estudantes informaram aspectos interessantes como:

“(...) o óleo não polui só os rios, mas também a terra” (E7)

“(...) este óleo polui os rios e algumas vezes, o mar.(...) as pessoas e o governo deveriam se unir para tratar deste assunto (...). (E9)

"(...) pode causar a poluição dos rios e também pode nos prejudicar." (E6)

"Deveríamos ter mais consciência desses assuntos." (E5)

No entendimento de Dias (2003, citado por SCHMOELLER, 2007) com a crescente problemática ecológica no mundo contemporâneo a Educação Ambiental vem no sentido de trazer novas ideias para conservação do meio ambiente, o uso equilibrado dos recursos naturais, a redução dos níveis de poluição produzidos pela população mundial, Poe meio da conscientização e sensibilização dos mesmos e de nada adianta termos desenvolvimento econômico sem o desenvolvimento social. Também de nada adianta termos os dois sem que tenhamos um ambiente saudável e ecologicamente equilibrado. E Jacobi (2005, p.247), segue afirmando que "a Educação Ambiental aponta para a necessidade de elaboração de propostas pedagógicas centradas na conscientização, mudança de atitude e práticas sociais, desenvolvimento de conhecimentos, capacidade de avaliação e participação."

Os alunos conscientizaram-se de que pequenas ações no cotidiano do lar podem gerar consequências em grandes proporções uma vez que o óleo lançado na pia segue caminho da tubulação até alcançar os recursos hídricos:

“(...) só agora as pessoas perceberam que jogando o óleo na pia o óleo vai para os rios prejudicando a nós mesmos." (E6)

Houve também reflexões muito bem estruturadas e ampliadas como:

"A consequência é que o óleo vai para os rios, como o óleo é menos denso que a água ele fica por cima, assim as algas marinhas...fazer a fotossíntese" (E1).

Ao discutir sobre a possibilidade de reciclagem do óleo de cozinha os estudantes concluíram que o sabão não era a única e melhor alternativa da reciclagem do óleo por não ser biodegradável. E é nessa direção que Rabelo e Ferreira (2010) se expressam ao relatar que há alternativas mais viáveis para a reciclagem do óleo como biodiesel, ração animal, entre outros. 
Os estudantes (E1, E2, E3, E4, E5, E6, E9), ou seja, 70\% da amostra obtiveram crescimento na conscientização em relação à necessidade da divulgação do assunto e inclusive com o envolvimento da comunidade.

Uma estudante evidenciou que as ações realizadas pelos pesquisadores no período de intervenção foram de muita relevância e lamenta o fato de que o trabalho não envolva mais pessoas:

"(...) antes não existia, mas agora com vocês existe! é bom, mas dá chance para poucos" (E8).

“(...) a sociedade poderia construir outras ideias sobre 0 descarte do óleo para que todos saibam o que está acontecendo e pode acontecer com o nosso mundo" (E1).

"(...) o governo poderia fazer isso pra gente" (E2).

O desafio ético-político da Educação Ambiental pode ser apoiado pelo potencial transformador das relações sociais e encontra-se estreitamente vinculado ao processo de construção e enraizamento da democracia e de uma cidadania ambiental. Para que as políticas públicas em favor do meio ambiente tornem-se uma realidade o papel dos professores é essencial no impulsionar dessas transformações citadas pelos estudantes. Precisamos de uma educação que assuma um compromisso com uma visão crítica, pautada em valores e de uma sociedade ambientalmente sustentável (JACOBI, 2005).

A Educação Ambiental é um assunto de extrema importância que requer um envolvimento conjunto de todos os setores da sociedade e os resultados produzidos são de extraordinário valor. Nessa questão não bastam ações solitárias. A consciência desta necessidade é um dos pontos marcantes manifestado pelos estudantes, pois além de uma melhora qualitativa no discurso sobre o assunto eles não expressam que os "outros" devem exercer essas ações, como se a preservação ambiental ocorresse alheia e distante deles. Os próprios estudantes se inserem nesse processo como sujeitos da ação:

"Sim, tudo isso é muito importante porque abraçando o planeta nós ainda podemos salvá-lo (...) somos o futuro e temos que fazer a diferença" (E7).

“(...) o meio ambiente faz parte de nossa vida, (...) porque se não tivermos um ambiente saudável, não teremos uma vida saudável" (E2).

“(...) todos nós temos que ajudar o planeta, (...) ele (...) é de todos nós. (...) se conservarmos o nosso mundo ele será melhor" (E8). 
Nos dias atuais não devemos negligenciar a educação quanto ao descarte indevido de resíduos potencialmente poluentes, que podem causar danos irreversíveis ao meio ambiente e a nós mesmos. Pequenas ações impensadas acarretam danos ao meio ambiente, porém um programa de educação bem estruturado traz conhecimentos decisivos e a consciência para um novo estilo de vida que possibilite a sobrevivência de uma gama de indivíduos que dependem dos recursos naturais em equilíbrio para sobreviverem.

O educador Paulo Freire sempre nutriu profundo respeito por todas as formas de vida e seus estudos subsidiam os debates e a criticidade necessária aos processos de Educação Ambiental:

Sua análise mantém em relevo a ideia de que os problemas ambientais, na sua maioria, não são apenas resultado de fenômenos naturais ou de forças divinas, mas, sim, de intervenção humana, cujas intencionalidades respondem a um modelo de vida predatório, produzido ao longo dos tempos. Tampouco somente pela sua rigorosa concepção de natureza humana, em processo de vir-a-ser no mundo e com o mundo, fazendo-se pela educação que, respeitosa dessa natureza, é problematizadora em sua radicalidade (PITANO; NOAL, 2009, p.285).

A Educação Ambiental é uma ferramenta de grande importância ao estímulo da conscientização ecológica e a melhoria da qualidade de vida, construindo atitudes que visem o desenvolvimento sustentável (RABELO E FERREIRA, 2010).

Portanto faz-se necessário planejar e incluir projetos estruturados voltados à Educação Ambiental, auxiliando e minimizando o quadro de poluição tão comum em nossos dias.

\section{CONCLUSÃO}

Nessa investigação constatou-se a melhoria qualitativa nas opiniões e percepções dos alunos em questão, registrando a relevância de incluir a Educação Ambiental como assunto transversal de maneira mais efetiva e estruturada no espaço escolar. Concluímos também a importância de abordar 0 tema do descarte indevido do óleo e seus efeitos deletérios no meio ambiente.

Inferimos que os objetivos educacionais mais importantes para a Educação Ambiental nessa questão referem-se ao desenvolvimento de mais iniciativas e ações de preservação e da capacidade de decidir e persistir na execução de uma tarefa. Ao findar da presente pesquisa propomos às instituições de ensino políticas para a implementação da Educação Ambiental no ambiente escolar, promovendo o desenvolvimento crítico e ações conscientes. Esperamos que mais investigações ocorram no espaço das salas 
de aula para buscar novos caminhos e proposições assertivas para a Educação Ambiental na contemporaneidade.

Concluímos com uma advertência de Kawasaki e Carvalho (2009) apresentada em um dossiê de estudos sobre a temática que podem nos induzir a uma reflexão maior sobre a "dificuldade em desenvolver pesquisas em EA a partir de práticas educativas, já que tais trabalhos não conseguem superar a condição de um simples relato da experiência concreta" o que remete à necessidade de "reflexões mais aprofundadas e teorizações sobre essa experiência, aumentando o fosso existente entre a teoria e a prática nesse contexto de pesquisa." (p.146).

\section{REFERÊNCIAS}

BRASIL. Resolução no 275, de 25 de abril de 2001 do Conselho Nacional do Meio Ambiente (CONAMA).

BRASIL. Lei 3325/99 de 17 de dezembro de1999. Rio de Janeiro. Dispõe sobre a Educação Ambiental, institui a política estadual de Educação Ambiental, cria o programa estadual de Educação Ambiental e complementa a lei federal № 9795/99 no âmbito do estado do Rio de Janeiro.

BRASIL. Projeto de Lei №. 166/2007. Amazonas. Dispõe sobre a instituição do programa para a destinação e recolhimento de óleo ou gordura utilizado na fritura de alimentos em nossa cidade e dá outras providências.

CANAL RURAL. Óleo de fritura contamina o meio ambiente. Disponível em:<www.canalrural.com>acesso em 28/07/2010.

RESTREPO, J.E. El desarrollo sostenible y el reciclaje del aceite usado de cocina a la luz de la jurisprudencia y el ordenamiento jurídico colombiano. Rev. P+L [online]. 2012, vol.7, n.1, pp. 109-122.

FERNANDES, R.K.M. et al. Biodiesel a partir de óleo residual de fritura: alternativa energética e desenvolvimento socioambiental. Anais do XXVIII Encontro Nacional de Engenharia de Produção, Rio de Janeiro, outubro 2008, p.1-10.

FREIRE, P. Educação e Mudança. Rio de Janeiro: Editora Paz e Terra, 1983.

GATTI, B. Grupo focal na pesquisa em ciências sociais e humanas. Brasília: Plano, 2005.

GONÇALVES, D.R.P. Educação Ambiental: Garantia de Vida. Niterói, RJ: Universidade Federal FLuminense,UFF. Dissertação de Mestrado em Educação,1984.

GUIMARÃES, M. A Dimensão Ambiental na Educação. Campinas, SP: Papirus, 1995. 
JACOBI, P.R.. Educação Ambiental: O desafio da construção do pensamento crítico, complexo e reflexivo. Educação e Pesquisa, São Paulo, n.2, v.31, maio/ago, 2005, pp. 235-250.

KAWASAKI, C.S.; CARVALHO, L.M. Tendências da Pesquisa em Educação Ambiental. Educação em Revista, Belo Horizonte, v.25, n.03, pp.143-157, dez. 2009.

ODUM, E. Ecologia. Rio de Janeiro-RJ: Editora Guanabara Koogan. 1988.

ODUM, E. Fundamentos de Ecologia. Lisboa: Editora da Fundação Calouste Gulbenkian, 2004.

PITANO, S.C.; NOAL, R.E. Horizontes de diálogo em Educação Ambiental: contribuições de Milton Santos, Jean Jacques Rousseau e Paulo Freire. Educação em Revista, Belo Horizonte, v.25, n.03, pp.283-298, dez. 2009.

PRADO. L.R. Curso de Direito Penal Brasileiro. v.1 São Paulo:RT Edições, 2006.

RABELO, R.; FERREIRA, O. Coleta Seletiva de Óleo Residual de Fritura para aproveitamento Industrial. Disponível em: www.ambientebrasil.com.br acesso em novembro de 2010.

RIO DE JANEIRO, Agenda 21- Conferência das Nações Unidas sobre Meio Ambiente e Desenvolvimento, 1992.

SCHMOELLER, F. Educação Ambiental e Gerenciamento de Resíduos Sólidos na Rede de Supermercados Giassi e Cia Ltda. Criciúma,S.C:Universidade do Extremo Sul Catarinense- UNESC. Trabalho de Conclusão do Curso de Engenharia Ambiental, 2007.

SEGATTO, F.B.B. Conhecendo as formas de descartes do óleo saturado de cozinha para verificar a Educação Ambiental na escola. RGET/UFSM, v.10, n.10, pp.2122-2129, jan 2013.

TRIGUEIRO, A. Mundo Sustentável: Abrindo Espaço na Mídia para um Planeta em Transformação. São Paulo: Editora Globo, 2005. 